\title{
Nutritive value of red vine husks and pips for sheep
}

\author{
A.V. Ferreira ${ }^{\#}$ \\ Department of Animal Sciences, Faculty of Agricultural and Forestry Sciences, University of Stellenbosch, \\ Private Bag X1, Matieland 7602, South Africa
}

\begin{abstract}
The potential of red vine husks and pips as a component of animal feed was investigated. Twenty-five Dohne Merino ram lambs (mean live weight \pm s.d. $=41.4 \pm 2.3 \mathrm{~kg}$ ) were used. A completely randomised design was used and the animals were assigned to five diets including $0,12.5,25.0,37.5$ and 50\% vine husks and pips together with pelleted lucerne hay, respectively. The voluntary intake of feed and water were not negatively influenced by the percentage vine husks and pips included in the diet. The digestibility of the crude protein, neutral detergent fibre and acid detergent fibre decreased significantly, while the dry matter digestibility showed a strong tendency towards a lower digestibility as the percentage vine husks and pips increased in the diet. According to the plasma metabolites, no toxic effects were evident in this study.
\end{abstract}

Keywords: Intake, tannins, digestibility, toxic effects

\#Corresponding author. E-mail: avf@sun.ac.za

\section{Introduction}

Grapes are widely grown in the Mediterranean area of South Africa, producing considerable quantities of by-products. Traditionally the vine husks is dumped or used as compost after the production of wine. Tannins, a naturally-occurring polyphenolic in vine by-products, form complexes with proteins, polysaccharides, amino acids, fatty acids and nucleic acids (Flores et al., 1994). Both the composition and the extent of polymerisation of tannins are important in determining their ability to form such complexes. In addition, a high tannin level in forage impairs palatability, digestibility and voluntary intake (Silanikove et al., 2001). There is a lack of information regarding the nutritive value of vine husks and pips for sheep. This shortcoming complicates recommendations for the use of vine husks and pips as supplementary feeding. In order to determine the potential of vine husks and pips as a component of feeds for ruminants, a trial was conducted to determine the intake, digestibility and toxic effects of vine husks and pips when fed at increasing levels in a mixed diet with lucerne hay.

\section{Materials and Methods}

Vine husks and pips, after pressing four red wine cultivars (Merlot, Shiraz, Carignan and Cabernet Sauvignon), were dried, pooled in equal amounts, mixed and pelleted. The basal diet, pelleted lucerne hay, was then supplemented with the vine husks and pips in such a way that it contributed 0, 12.5, 25.0, 37.5 and $50.0 \%$ of total dry matter (DM) intake, respectively. Twenty-five Dohne merino ram lambs (mean live weight \pm s.d. $=41.4 \pm 2.3 \mathrm{~kg}$ ) were used in the trials. A completely randomised design was used and the animals were assigned to five diets consisting of $0,12.5,25.0,37.5$ and $50 \%$ vine husks, respectively. Animals were kept in individual pens and fed on an ad libitum basis. During the voluntary intake trial, which lasted 35 days (14 days for adaptation and 21 days for the recording of voluntary intake), daily water and DM intake were measured. Sheep were fed once daily and had free access to water. The digestibility trial lasted 21 days (14 days for adaptation and seven days for the experiment). Feed was offered at an intake level close to maintenance (40-45 g DM/kg LW ${ }^{0.75}$ per day) as recommended by Van Es \& Van der Meer (1980). Faeces were collected daily from each animal and dried in a drying oven for $96 \mathrm{~h}$ at $50{ }^{\circ} \mathrm{C}$ and ground through a $1 \mathrm{~mm}$ screen. Daily faecal and feed samples were analysed for DM, ash, CP and ether extract (EE) according to AOAC (1984) methods. To determine NDF and ADF the methods proposed by Van Soest et al. (1991) were followed. Acid-detergent insoluble nitrogen (ADIN) was measured (Licitra et al., 1996), and the value was given in terms of crude protein (ADF-CP). Blood samples (10 mL) were taken from each sheep at the end of the digestibility trail. Blood was taken from the jugular vein into heparinized tubes and centrifuged for 20 minutes at 3000 revolutions per minute to separate the plasma, which was stored at $-20^{\circ} \mathrm{C}$. The plasma was analyzed according to procedures conventionally used for diagnosing domestic animal hepatic and kidney damage and general disorders (Kaneko, 1989). Components measured were total protein, plasma urea nitrogen and creatinine. In addition, the plasma enzymes aspartate aminotransferase 
Peer-reviewed paper: Joint South African Society for Animal Science/Grassland Society of Southern Africa Congress

(EC: 2.6.1.1) (AST) and gamma glutamyltranspeptidase (EC: 2.3.2.2) (GGT) were measured. The sorghum tannin equivalents method was used for determination of condensed tannins (Hagerman, 1995). Analyses of variance were performed on all the variables measured using the General Linear Models (GLM) procedure of SAS (1990).

\section{Results and Discussion}

The chemical composition of the five diets, as well as the vine husks and pips, is shown in Table 1 . The protein content decreased as the percentage vine husks and pips increased in the diet, while the CP-ADF (protein attached to cell walls, and therefore indigestible) increased. There was also a marked increase in the condensed tannin content as the percentage vine husks and pips increased in the diets. The condensed tannins bind to proteins and sometimes may reduce protein digestibility (Silanikove et al., 2001).

Table 1 Physical (on an air dry basis) composition and chemical (on a dry matter basis) composition of the experimental diets

\begin{tabular}{lcccccc}
\hline Experimental diet & 1 & 2 & 3 & 4 & 5 & $\begin{array}{c}\text { Vine husks and } \\
\text { pips }\end{array}$ \\
\hline Ingredients (kg/1000 kg) & 1000 & 875 & 750 & 625 & 500 & \\
Lucerne hay & 0 & 125 & 250 & 375 & 500 & \\
Vine husks and pips & & & & & & \\
Chemical composition (g/kg) & 925 & 921 & 920 & 920 & 924 & 923 \\
Dry matter & 889 & 894 & 891 & 907 & 920 & 929 \\
Organic matter & 111 & 106 & 109 & 93 & 80 & 71 \\
Ash & 182 & 179 & 172 & 162 & 151 & 137 \\
Crude protein & 440 & 434 & 438 & 439 & 436 & 433 \\
Neutral detergent fibre & 334 & 345 & 363 & 370 & 385 & 434 \\
Acid detergent fibre & 3.2 & 4.3 & 4.8 & 5.7 & 5.5 & 9.8 \\
CP-ADF (g/100 g CP ${ }^{1}$ ) & 24 & 34 & 46 & 69 & 72 & 110 \\
Ether extract (fat) & 0.7 & 2.4 & 4.1 & 5.7 & 7.4 & 14.1 \\
Total condensed tannins, g STE ${ }^{2}$ & 0.7 & & &
\end{tabular}

Table 2 Average feed intake, water intake and blood metabolic profile of sheep fed the different diets

\begin{tabular}{|c|c|c|c|c|c|c|c|}
\hline \multirow[t]{2}{*}{ Item } & \multicolumn{7}{|c|}{ Lucerne hay: Vine husks and pips } \\
\hline & 100:0 & 87.5:12.5 & $75: 25$ & $62.5: 37.5$ & $50: 50$ & s.e. ${ }^{3}$ & $\mathrm{P}$ \\
\hline Initial body weight, $\mathrm{kg}$ & 41.7 & 41.4 & 41.4 & 41.5 & 40.8 & 2.25 & 0.99 \\
\hline Final body weight, kg & 45.0 & 44.6 & 43.3 & 43.8 & 41.5 & 2.40 & 0.85 \\
\hline DM intake $\mathrm{kg} / \mathrm{W}^{0.75}$, g/day & 110 & 116 & 114 & 117 & 119 & 0.77 & 0.94 \\
\hline Water intake $\mathrm{kg} / \mathrm{W}^{0.75}, \mathrm{~mL} /$ day & 456 & 444 & 458 & 407 & 376 & 32.74 & 0.46 \\
\hline Blood urea nitrogen, $\mathrm{mg} / 100 \mathrm{~mL}$ & $9.6^{\mathrm{a}}$ & $7.4^{\mathrm{b}}$ & $7.5^{\mathrm{b}}$ & $6.4^{\mathrm{b}}$ & $6.7^{\mathrm{b}}$ & 0.73 & 0.05 \\
\hline Total protein, mg 100/mL & 68.0 & 67.5 & 69.8 & 71.3 & 68.3 & 2.36 & 0.79 \\
\hline Creatinine, mg 100/mL & 118.8 & 122.0 & 119.3 & 125.3 & 124.8 & 5.50 & 0.87 \\
\hline AST $^{1}$, units/L & 75.8 & 93.3 & 73.5 & 80.5 & 89.8 & 6.25 & 0.25 \\
\hline $\mathrm{GGT}^{2}$, units/L & 80.5 & 70.0 & 72.0 & 76.0 & 68.5 & 4.26 & 0.31 \\
\hline
\end{tabular}

According to Table 2, the voluntary intake of feed and water were not significantly ( $\mathrm{P} \geq 0.05$ ) influenced by the percentage vine husks and pips included in the diet. The final body weight was also not negatively influenced $(P \geq 0.05)$ by the inclusion of vine husks and pips up to $50 \%$ of the diet. The presence of tannins in forage has been assumed to affect voluntary intake (McLeod, 1974). However, in this trial intake problems were not observed with inclusion levels of up to $50 \%$ of diet dry matter. There were no differences between diets in any plasma metabolite except for blood urea nitrogen (Table 2). An increase of creatinine can be related with renal failure, but the level found in the present study fell within the normal range for sheep (Kaneko, 1989). No significant changes in plasma enzymes AST and GGT were found. These enzymes are used to detect if tannin-related hepatotoxicity occurred (Zhu \& Filippish, 1992). In sheep 
Peer-reviewed paper: Joint South African Society for Animal Science/Grassland Society of Southern Africa Congress

fed with lucerne hay, the blood urea nitrogen concentration was higher $(\mathrm{P} \leq 0.05)$ than in sheep fed with the diets where vine husks and pips were included, which is directly related to the limitation in protein digestibility in sheep fed vine husks and pips.

The digestibility of the CP, NDF and ADF decreased significantly, while the DM digestibility showed a strong tendency towards a lower digestibility as the percentage vine husks and pips increased in the diet (Table 3). This result may be due to several factors. Firstly, the vine husks and pips had a much higher level of CP-ADF (crude protein bound to the indigestible fibre fraction) than that of lucerne hay $(71.5 \%$ vs. $17.6 \%$ of the total protein is bound to the fibre). Secondly, it could be due to the presence of condensed tannins in the vine husks and pips. These compounds form complexes with proteins and carbohydrates (Makkar et al., 1996), decreasing the available protein and energy for rumen micro-organisms (Silanikove et al., 1994).

Table 3 Apparent digestion coefficients of the diets

\begin{tabular}{lccccccc}
\hline Apparent digestibility (\%) & \multicolumn{7}{c}{ Lucerne hay: Vine husks and pips } \\
& $100: 0$ & $87.5: 12.5$ & $75: 25$ & $62.5: 37.5$ & $50: 50$ & s.e. & P \\
\hline Dry matter & 57.1 & 53.9 & 50.4 & 46.8 & 48.0 & 2.45 & 0.053 \\
Crude protein & $68.4^{\mathrm{a}}$ & $64.2^{\mathrm{ab}}$ & $59.0^{\mathrm{b}}$ & $56.3^{\mathrm{bc}}$ & $52.5^{\mathrm{c}}$ & 1.91 & 0.0002 \\
Neutral detergent fibre & $42.6^{\mathrm{a}}$ & $33.5^{\mathrm{b}}$ & $32.3^{\mathrm{b}}$ & $23.9^{\mathrm{c}}$ & $18.5^{\mathrm{c}}$ & 2.12 & $<0.0001$ \\
Acid detergent fibre & $39.9^{\mathrm{a}}$ & $26.4^{\mathrm{b}}$ & $23.7^{\mathrm{bc}}$ & $17.1^{\mathrm{cd}}$ & $12.8^{\mathrm{d}}$ & 3.21 & 0.0003 \\
Ether extract (fat) & $39.3^{\mathrm{a}}$ & $66.1^{\mathrm{b}}$ & $77.7^{\mathrm{c}}$ & $82.6^{\mathrm{c}}$ & $79.0^{\mathrm{c}}$ & 3.82 & $<0.0001$ \\
\hline
\end{tabular}

$\overline{\mathrm{a}, \mathrm{b}, \mathrm{c}}$ Values in rows bearing different superscript letters show significant $(\mathrm{P} \leq 0.05)$ differences

\section{Conclusions}

Voluntary intake of feed and water were not negatively influenced by the inclusion of up to $50 \%$ vine husks and pips in the diet. The decrease in diet digestibility as the percentage inclusion of vine husks and pips increased may be due to factors such as the high levels of proteins bound to the ADF and condensed tannins. However, an inclusion up to 50\% in the diet had no toxic effects. Vine husks may therefore play an important role as supplementary feeding in the Mediterranean sheep farming areas of South Africa.

\section{References}

AOAC, 1984. Official Methods and Analysis, $15^{\text {th }}$ Ed. Association of Official Analytical Chemists, Washington, DC. pp. 1141.

Flores, M.P., Castanon, J.I.L. \& McNab, J.M., 1994. Effect of tannins on starch digestibility and TMEn of triticale and semi-purified starches from triticale and field beans. Br. Poult. Sci. 35, 281-286.

Hagerman, A.E., 1995. Tannin handbook. Miami University, Ohio, USA. http://www.muohio.edu/hagermae.

Kaneko, J.J., 1989. Clinical Biochemistry of Domestic Animals, $4^{\text {th }}$ Edition. Academic Press, New York. pp. 932.

Licitra, G., Hernández, T.M. \& Van Soest, P.J., 1996. Standardization of procedures for nitrogen fractionation of ruminal feeds. Anim. Feed Sci. Technol. 57, 347-358.

Makkar, H.P.S., Goodchild, A.V. \& Abd El-Moneim, A.M., 1996. Cell-constituents, tannin levels by chemical biological assays and nutritional value of some legume foliage and straws. J. Sci. Food Agric. 71, 129-136.

McLeod, M.N., 1974. Plant tannins - their role in forage quality. Nutr. Abst. Rev. 44, 803-815.

Silanikove, N., Nitsan, Z. \& Perevolotsky, A., 1994. Effect of polyethylene glycol supplementation on intake and digestion of tannin-containing leaves (Ceratonia siliqua) by sheep. J. Agric. Food Chem. 42, 2844-2847.

Silanikove, N., Perevolotsky, A. \& Provenza, F. D., 2001. Use of tannin-binding chemicals to assay for tannins and their negative postingestive effects in ruminants. Anim. Feed Sci. Tech. 91, 69-81.

SAS, 1990. Statistical Analysis Systems (SAS/STAT) user's guide. Version 6 (4th ed.). SAS Inc. Cary. pp. 891.

Van Es, A.J.H. \& Van der Meer, J.M., 1980. Methods of analysis for predicting the energy and protein value of feeds for farm animals. In: Proceeding of the $31^{\text {st }}$ Annual Meeting, EAAP, Netherlands. pp. 39-43.

Van Soest, P.J., Robertson, J.B. \& Lewis, B.A., 1991. Methods for dietary fiber, neutral detergent fiber and nonstarch polysaccharides in relation to animal nutrition. J. Dairy Sci. 74, 3583-3597.

Zhu, J. \& Filippish, L.J., 1992. Tannic acid intoxication in sheep and mice. Res. Vet. Sci. 63, 280-292. 